AdRIANA KiCZKOWSKI

UNED. Universidad Nacional de Educación a Distancia*

iD https://orcid.org/0000-0003-0566-0334

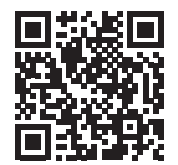

\title{
Fact and Fiction in a Robotic Society from a Feminist Perspective
}

\begin{abstract}
A new narrative of care for the elderly is being constructed in both fiction and our techno-societies that incorporates the use of robots in areas traditionally entrusted to women, reproducing some of the stereotypes historically attributed to them. I propose to analyse representations of robots designed for elder care in the field of science fiction, like in the case of the TV series Real Humans (2012), as well as "real" robots. My aim is to highlight the risks of reproducing gender bias in robotics, where women could continue to perpetuate their role as caregivers. The objective is to show the need to develop a gender perspective in robotics applied to the care of the elderly that will make it possible to change the status quo.
\end{abstract}


* Departamento de Filologías Extranjeras y sus Lingüísticas, Facultad de Filología, Universidad Nacional de Educación a Distancia

Senda del Rey, 7, 28040 Madrid, Spain

e-mail: adrianaky@flog.uned.es

The research resulting in this article relates to the project "Multiple voices, plural knowledges and biomedical technologies (VOSATEC)", funded by the Spanish Ministerio de Ciencia, Innovación y Universidades (2015-65947-C2-1-P). 
In order to understand the enormous impact the high degree of development reached in advanced robotics is having on our lives, it is very useful to analyse the practices, ideological commitments and values on which these devices have been built, as well as how this social influence is expressed and reflected in fictional spaces such as TV series.

An important part of research and current developments in the field of robotics are focused on the care of the elderly, or "technocare" as Cordula Endler (2019) suggests calling it, which is a particularly relevant case that shows the interrelationship between the development of technology and the social values that guide it. Statistics show the progressive aging of the world population, so the technology industry in countries such as Japan, the United States or in the European Union is betting on the development of robots to provide a solution for the expected future demand in care for the elderly. However, beyond this quantitative perspective on aging and the corresponding needs that are produced, it is quite relevant to pay attention to the social construction of aging in an era of profound technological changes. There will not only be increasingly more elderly people in our societies, but we also expect them to have a healthy life, risk-free, and we dream of this being possible in a technologically advanced society. And as in Goya's painting, the illusion of reason produces monsters.

On the other hand, it should be remembered that taking care of the elderly has traditionally been assigned to women. Despite the enormous social transformations in the area of women's rights achieved in the last decades, it is undeniable that much of the care of the elderly continues to be borne by women, either due to family obligations or because a large part of the health workers who deal with these tasks are women (nurses, caregivers, etc.).

Joyce, Leo and Diamond-Brown, in their article "Science, Technology and Aging" (2015), point out the importance of analysing technological developments in the field of elder care from a feminist approach. The gender perspective can help in taking another look at ageism, which is often considered a universal and neutral problem. But when the relationships between techno-science, age and aging are analysed by incorporating issues such as masculinity, femininity, race or sexuality, the supposed neutrality is broken. Instead of the universalist view from nowhere defended by philosophers such as Thomas Nagel (1989) to analyse the objectivity of science and technology, it is more enlightening to adopt a vision that is closer to feminist epistemologies (Loh 2019) to analyse developments from Artificial Intelligence (AI) in the field of care. 
More than strengthening the value neutrality and objectivity of science and technology, developments in AI, the ubiquity of algorithms, and the growing expansion of a hybrid cyber-society all clearly show that the feminist critique was pointing to a problem that went beyond the inevitable gender point of view, moving deeper into the value-laden practice of science and technology (Coeckerlbergh 2019). There is little doubt that the lines of technological evolution are very dependent on hegemonic values in a given society. Of course, there is a lot of evidence of gender bias in robotics. But beyond such bias in a particular device, the problem is more general because it affects the social construction of a cyber world that inherits many of the inequalities and deficiencies seen in the industrial world.

Given this evidence of gender bias in robotics, the goal must be to avoid reproducing a framework in which women continue to be perpetuated in their role as caretakers, and to ensure that digital assistive technology or robotics applied to care reflects a gender perspective capable of modifying the status quo.

An important space to start this reflection can be found in contemporary science fiction, as it outlines utopian and dystopic environments that can be of interest in evaluating practices and technological developments from a gender perspective. The general perspective presented to us in narratives, which go beyond the insertion of more or less surprising technological details that can have greater or lesser global coherence and meaning, leads us to consider global reflections on the shaping of society and technology, which in the end is an indispensable critical piece for acting in our techno-societies.

My objective here is to analyse a television show that describes the experiences of people living with robots designed for their care, in particular, for the elderly. Specifically, I will focus on the Swedish television series Real Humans (2012) and its English remake Humans (2015) to analyse how values, stereotypes and gender bias traditionally linked to the field of care are transferred to robotics. In my opinion, an analysis of the way in which television fiction or cinema represent this subject can be a good point of contrast with reality. This is because, additionally, this type of fiction places subjects into the sphere of public opinion that then advance socially, almost imperceptibly, but end up being present and transforming our social practices. It is important to give warning from a gender perspective about the ethical and political elements of major technological decisions. The contrast between the work of fiction and the real, actual developments that are taking place in the research and implementation of this technology in our care centres for the elderly and in homecare is particularly illustrative and significant.

It is almost commonplace to talk about issues related to the possibility of humans building intelligent life, referring to Frankenstein. Mary Shelley's romantic Prometheus is undoubtedly the model, the prototype that permeates a great part of the representations in science fiction, whether novels or films, and with few variations over the years. Literature, cinema and, in recent decades, TV, through the prolific genre of science fiction, have been increasingly showing many of the aspects related to the debate on robotics, reflecting the various ethical approaches and the political, economic and ideological interests that are at stake in the attempt to create life in the image and likeness of humans. However, today, regarding robotics, the boundaries between what is hypothetical and what is real seem to fade away. As Donna Haraway pointed out in her famous A Cyborg Manifesto "the boundary between science fiction and social reality is an optical illusion” (1985: 149). 
Robotics, which began developing as military technology, is being transformed or expanding its base of implementation for professional and domestic services. With the development of cloud technologies and the Internet of Things (IoT), today we already find ourselves in the implementation and generalization phase for many devices in the home that had seemed to still be fictional. In health care, this development is partly justified by the demographic trend, which presents itself as an inevitable crisis in which the growing number of elderly people will have to be cared for by an ever-smaller number of young people. As samples of solutions in progress, first some programs financed by the European Union under the $7^{\text {th }}$ Framework Programme in ICT (Information and Communication Technologies) can be mentioned, continuing with the Horizon 2020 Program and the subsequent plan 2020-2025 Horizon Europe.

There are already a good number of projects that are seeing results and producing lines of technological intervention on aging. For example, the CompanionAble Project, coordinated by the University of Reading (UK) 2008-2012, and the GiraffPlus project coordinated by Örebro University (Sweden) 2012-2015 can be considered pioneers in Europe. In both projects the robots share some features, as they are devices on wheels having a screen rather than a face to interact with their different functions as well as with applications for communication, such as videoconferences. Hector, which is the name of the CompanionAble $\operatorname{robot}^{1}$, has eyes, located above the screen, used to actively search for a person and remember the contact. On the project website, the robot is presented as an unproblematic solution. We can also mention another project, Rose ${ }^{2}$, which is testing robots as caretakers in the Netherlands, or another Rose ${ }^{3}$ in Finland. And, of course, outside the European Union the development of robots is getting a huge boost. We can find many examples in Japan, Korea, Australia or the United States.

The images that can be seen of these robots for social care (webpages, advertisements, etc.) share the same features, elderly people look happy with them, all of them are laughing no matter where they are or what illness they suffer from. These types of artifacts have multiplied in recent years. For example, RUDY ${ }^{4}$ is an AI-enabled mobile solution that helps users remain physically healthy, mentally sharp, and socially connected. Also the Canadian robot called Zora ${ }^{5}$, "the world's first humanoid robot, active in healthcare" as it is defined in its Twitter profile. As Cordula Endler says, "the pre-configuration of age as decline, illness and vulnerability in the policy agendas and the public discourse is repeated in applications and project proposals and determines the technology that is invented (2019: 137).

Television fiction is also no longer thinking of robotics as a future possibility or as something very remote, but rather as a feasible fact now subject to discussions of ethical, political or economic rather than scientific factors. This is the case of Real Humans, which can be presented as an example of how a new narrative of care is being constructed that incorporates the use of robots into areas traditionally entrusted to women or to people with lower resources and a lower educational level and, in the case of Europe, specifically the immigrant population.

\footnotetext{
https://www.robotcenter.co.uk/products/hector.

http://robot-rose.com/?lang=en.

http://roseproject.aalto.fi/en/.

https://infrobotics.com/\#rudy.

@zora_robot.
} 
Real Humans is a program from Swedish TV that was released in 2012 and has been broadcast for two seasons. There is also a British-American remake, Humans, whose first season was shown in 2015 on AMC and Channel 4. The fiction takes place in a kind of parallel present, in an environment that could be any European or Western country, but in which we find the existence of human-like robots cohabitating with us in our societies, performing a wide range of activities usually performed by humans.

Androids and gynoids - the bubots as they call them in Real Humans (a combination of humans and robots) - or the synthetics (as the English call them), work in factories, in the countryside, on farms, cleaning cities, in brothels, etc. In general, all robots are handsome, young, with slim bodies. In the first scene of the series a TV commercial is seen promoting robots and the wonders they are always able to perform, which are emphasised with the kind of adjectives we would use to "advertise" the skills of a person prepared for a particular job. The physical attributes highlighted respond to social stereotypes related to beauty, youth, efficiency, kindness, empathy, etc. The uniforms they use for the jobs they are doing also reproduce the usual styles among humans. Even the gynoid that appears in the series to take care of an old man exploits another female stereotype, this time related to the image of nurse, woman, old, fat, authoritarian.

The definition of humankind and the definition of human singularity is a central theme in Real Humans, and many traditional questions studied by philosophy in ancient times appear. These are questions that have always concerned science fiction and now arise in the negotiation of the relationship between humans and machines: the difference between humans and machines, what makes us human, what elements define human beings, can machines have a soul, feelings or emotions, etc.

A large part of human activities will be carried out by robots with the consequent possible loss in the meaning of life, as Real Humans shows, to the extent that the hubots perform perfectly well many of the tasks that have given meaning to human life. One of the main conflicts in the series' plot is the social acceptance or rejection of robots. In fact, part of the tension that connects the different chapters is based on two opposing groups, those who support, use and increasingly interrelate with robots and those who oppose their manufacture and cohabitation with them because they feel humans are being displaced, not only in terms of jobs but even in emotional relationships, whether among family or friends.

One of the issues I am interested in highlighting is precisely how the replacement of humans is especially noticeable when it comes to traditional women's roles. One of the subplots of the series presents a type of family that incorporates a hubot to perform household tasks (cleaning, cooking, etc.) as well as the care of children (take them to school, helping them with their homework, etc.). Anita is a young, beautiful, loving robot with a sweet voice, efficient, helpful, as opposed to Inger, the mother, who is a lawyer that spends many hours outside the home because of her job. The father is mainly responsible for all household tasks and care of their three children (two teenagers and a six-year-old girl). This man, burdened by domestic responsibilities, decides unilaterally to buy the robot with the illusion of being able to devote more and better time to his family. The mother does not initially approve of the arrival of a machine in the house, and this begins to create a series of role assignment conflicts.

The presence of a hubot in the house puts basic motherhood roles in question, especially when women work outside the home. What are the tasks that only a mother can do? Which of them can be replaced by a machine? The father demands free time to enjoy with his family 
without questioning that a machine can take away his role as a father or husband, while the mother's conflict is generated by the insecurity of not properly fulfilling her role as a mother, not taking care of her children as she should because she works and does not have enough time to pay attention to her daughter, which creates a feeling of guilt and, at the same time, jealousy because a machine can perform tasks that it would seem only a human can do. This is clearly reflected in some scenes, for example, the moment when the robot "Anita" reads a story to the little girl in the house, Sophie, and the mother gets angry because reading stories is part of the job of being a mother.

Sophie: Can Anita read [the story] instead?

Inge: I'll read the story. [...]

Sophie: She is never in a hurry like you are.

Inge: I'm a little tired, honey.

Sophie: You're always tired.

Inge: So, do you want me or Anita to read?

Sophie: Anita.

(Anita comes and starts to read the book)

Sophie: Don't you ever sleep?

(Real Humans, Chapter 1, min. 31:40-32:10)

This scene clearly shows the movement of Inge, the mother, from an activity that is supposed to be key in the relationship between parents and children, the moment of reading a story before going to sleep. An activity that is supposed to combine the intellectual content of the act of reading itself with the accompaniment before sleep, which corresponds to a moment of affection or emotional exchange. This moment of warmth, closely associated with motherhood, is replaced by a machine capable of reading without getting tired. The working mother arrives home tired and unable to give her daughter the attention she requires. The quality of the time a mother spends with her children is questioned, showing the difficulties of reconciling work and family care.

Another line of argument in the series discusses the possibility of machines serving as elder caregivers. An old man, Lennart Sollber, Inger's father, refuses to abandon Odi, his old hubot that has been damaged and must be replaced by a new model. With the former, who was young and boyish, Lennart had established an affectionate relationship; Odi replaces the memory Lennart is losing and was the witness to his previous life. But above all, Odi, a male hubot, was more a companion than a caretaker in activities like going fishing or designing boats. This is something that is going to change dramatically with the new hubot, who is a strong, adult woman in a maid or nurse's uniform.

The new robot that will take care of Lennart contrasts physically and emotionally with Lennart's weakness; he is a thin, fragile and vulnerable character that coincides with the characteristic representation of older people. When the social worker visits the (old) scientist to bring him a new hubot (robot) we can hear:

Social Worker: I have good news. You qualified for an upgrade ... can adjust your medication, develops exercise plans to reduce your risk, take your blood pressure with a finger... 
Lennart: She can check the prostate too? I'm happy with the one I have, and my health is quite fine.

Social Worker: The report says you suffer from memory loss and limb tremors. the law requires me to remove your partner. You will have one of these new ones whether you like it or not. The health service hasn't ordered half a million of them for fun.

(Humans, Chapter 1, min. 16:28-17:27)

Around Lennart's character, Real Humans shows important considerations and discussions on how values are incorporated into technology and integrated into the design and technological results. On the one hand is the tension between values and considerations for a satisfactory, happy life that is worth living for humans and, on the other, the absence or drastic reduction in freedom of choice by elderly people. This can be clearly seen in the discussions the character has with his new caretaker (woman-like robot) regarding what he should or should not eat.

(Lennart sits at the table and asks his caretaker robot)

Lennart: Where's the coffee?

Robot: You have hypertension, Lennart.

Lennart: How do you know?

Robot: I checked while you were sleeping. You get a cup of tea.

Lennart: I want my coffee.

Robot: It's not good for you.

Lennart: I want coffee, and I want to be left alone in the kitchen.

Robot: Try not to get agitated, remember the hypertension.

Lennart: Bitch.

(The robot serves him a cup of tea).

(Real Humans, Chapter 2, min. 12:40-13:45)

A similar conflict is found in other ways of using medical technology, which tends to erase people's ability to decide about their own body and health. Showing disregard for those receiving aid is a very widespread problem in care relationships. The problem has begun to be taken into account by public services and international institutions. For example, a Council of Europe report, Human rights of older persons and their comprehensive care, was created by the Committee on Social Affairs, Health and Sustainable Development, aiming to promote the human rights of older persons. The report was adopted by the Parliamentary Assembly of the Council of Europe on 30 May 2017. Among its objectives are:

Foster a person-centred approach in the provision of care, by organising it around the needs and preferences of older persons and involving them in its planning [...]. It is essential to move away from a needs-based approach that focuses on disease and functional dependency towards an allencompassing human rights-based approach in which the enjoyment of all human rights by older persons becomes an integral part of all policies and programmes affecting them, including care planning and delivery. Moreover, our goal should be to ensure not just a longer life but a better and healthier life. Therefore, it is important to promote healthy ageing and prevent people from becoming dependent on care. (Council of Europe 2017) 
In the same vein, María Isabel Aldinhas F. and Joao Silva Sequeira in their paper "Robots in Ageing Societies" point out that "the main objections that have been raised about the use of robotic technology with vulnerable older people are loss of social contact, deception and, in some cases, even infantilisation." (2017: 221). Real Humans invites us to ask the question about the purpose of technology that, while developing systems to help us is, at the same time, increasingly intrusive and leads to a kind of permanent vigilance. Lennart's new hubot, Vera, is infinitely more effective than the previous one, but it's not clear that she can take care of Lennart in the way he wants to be taken care of.

As many social services staff and family members of older people say, the benefits of robotic technologies for the care of the elderly are clear, but in the words of Aldinhas and Siqueira, four inalienable human rights have to be safeguarded: "The right to freedom, in all instances, to make their own choices, the right to privacy and intimacy at physical and psychological levels and the right to real interaction with other humans, and the inalienable right to love and be loved" (Aldinhas, Siqueira 2017: 222).

In the case of the Swedish series, Real Humans, the decision to buy a hubot for the grandfather is considered a family issue, with the consequent conflicts: just how to take care of our parents. In this case Inger, the main character, proposes bringing her father to live with them but in the end does not. In any case, it is a decision she has to live with, and she feels guilty for not being able to take care of her father and for having to leave him alone with the assistance of only a machine.

However, in the American-British version it is interesting to note that the decision regarding the care of elderly people is not a family affair; it comes from healthcare public services. Social services determine what type of robot each older person needs, and when. The assistance will be monitored, and the person will be under permanent surveillance. Older people are obliged to accept that they are assigned a caretaker-hubot over which they have no decision-making capacity. This leads directly to a reflection on the social limits and obligations taken on by the State.

Many critical voices have emerged about the relevance of robots as viable or appropriate responses to elder people's need for care. First, it is doubtful whether robots can make complex meals or do cleaning tasks in the near future, or that they can bathe, clothe, help with mobility and other caring tasks. Robots could be better suited for a number of other aspects, such as monitoring health and personal safety. They can measure physical health indicators such as blood pressure or activity patterns around the house. They can activate emergency warnings in case of a fall or warn if the kitchen stove has been left on. But it is not clear if robots could improve cheaper systems such as sensors, alarms, computers, mobile phones, etc. Robot-care for an invalid could be a great advantage but requires skills that have not yet materialized.

On the other hand, there is an ethical issue regarding the threat of using robots as opposed to contact with human caretakers. This becomes more worrying when it comes to accompanying older people. Sparrow and Sparrow (2006) assert that the use of robots would reflect a serious lack of respect for the elderly because the care would be instrumental, the person would be objectified as a problem to be solved instead of being thought of as a person who needs company. Sharkey (2014) qualifies this and considers that robots could facilitate social contact through videoconference applications or could even stimulate interaction with the robot that could serve to put the elderly in contact with other people. 
In any case, the approach with robotics tends to focus on the good and bad use of robots and on the individual rights of the elderly to proper care. This usually raises a dichotomy about cold machines, on one side, and human warmth on the other. However, at present we are not users of technology as mere instruments but have been constituted to a large extent like technological bodies. Everything we do and perceive is mediated by technology. Identity, then, could be raised in regard not to what differentiates us from robots, but who we are with robots and, hence, how older people can be in the company of robots.

Another aspect to think about is what model of human being is followed to design robots. To what extent can they contemplate different social, cultural contexts, as well as different experiences or life histories. Technologies are developed in specific cultural settings. The idea of what is normal and the stereotypes that characterize abnormality are quickly found in the design process. Moreover, to what extent is it possible to create "ethical robots" that incorporate the type of reflection and decision-making that is usually considered characteristic of emotional human behaviour and an ethical character as they appear in the hubots of Real Humans.

Finally, it seems necessary to pay attention to the social and ethical aspects of the use of robotics from and before its planning, design, and implementation. "Technologies are never merely technical or functional; they also actively produce and reproduce meaning, including gender meanings. But it also actively suggests the possibility of change [...] We can create different robots and use them differently" (Coeckelbergh 2019: 33). In my opinion, narrative representations such as the ones I have just commented on in relation to Real Humans are important because they foreshadow the conflicts produced by the displacement of humans in the activities that robots are doing, traditionally confined to the area of women, and there is a very particular tension in relation to the role of the State and the public institutions responsible for the design and implementation of medical care for citizens.

Reflecting on the gender bias in robotics could avoid the reproduction of a framework in which women are perpetuated as caretakers and, at the same time, could assure that robotics applied to care, in all its phases, takes on a gender perspective capable of modifying the status quo. My interest here has been to simply point out the pertinence of using the media to contribute to reflection on important political and ethical matters. It seems important to me to pay attention to narrative representations such as Real Humans because the conflicts created by the displacement of humans in caregiving activities, traditionally entrusted to the efforts and attention from women, are forcefully presented and suggested. It is, of course, interesting to trace a critical perspective on the use of robotics and, undoubtedly, fiction - like all artistic practices - offers us an excellent sphere to understand social questions. 


\section{Bibliography}

Aldinhas María I., Sequeira Joao S. (2017), Robots in Ageing Societies [in:] A World with Robots. Intelligent Systems, Control and Automation: Science and Engineering, eds. Aldinhas M., Sequeira J., Tokhi M., Kadar E., Virk G., Springer, Abbildungen.

Coeckelbergh Mark (2015), Technology Games/Gender Games. From Wittgenstein's Toolbox and Language Games to Gendered Robots and Biased Artificial Intelligence [in:] Feminist Philosophy of Technology, eds. Loh J., Coeckelbergh M., Metzler, Wien.

Council of the European Union. Resolution 2168 (2017), Human rights of older persons and their comprehensive care [in:] Text adopted by the Standing Committee, https://assembly.coe. $\mathrm{int} / \mathrm{nw} / \mathrm{xml} / \mathrm{XRef} / \mathrm{Xref-XML2HTML-EN.asp?fileid=23768 \& lang=en} \mathrm{[access:} \mathrm{7.07.2020].}$

Endler Cordula (2019), Becoming with Technology - the Reconfiguration of Age in the Development of a Digital Memory Training [in:] Feminist Philosophy of Technology, eds. Loh J., Coeckelbergh M., Metzler, Wien.

Haraway Donna (1986), A Cyborg Manifesto. Science, Technology, and Socialist-Feminism in the Late Twentieth Century [in:] Manifestly Haraway, ed. Haraway D., University of Minnesota Press, Minneapolis.

Joyce Kelly, Loe Meika, Diamon-Brown Lauren (2015), Science, Technology and ageing [in:] Routledge Handbook of Cultural Gerontology, eds. Twigg J., Martin W., Routledge, New York.

Joyce Kelly, Mamo Laura (2006), Graying the Cyborg: New directions in Feminist Analyses of Ageing, Science and Technology [in:] Age Matters. Realigning Feminist Thinking, eds. Calasanti T., Slevin K., Routledge, New York.

Loh Janina (2019), What Is Feminist Philosophy of Technology? A Critical Overview and a Plea for a Feminist Technoscientific Utopia [in:] Feminist Philosophy of Technology, eds. Loh J., Coeckelbergh M., Metzler, Wien.

Lundström Lars dir. (2012), Real Humans (Äkta människor), Sveriges Television (SVT).

Nagel Thomas (1989), The View from Nowhere, Oxford UP, Oxford.

Sharkey Amanda (2016), Should We Place Robots in Social Roles? [in:] What Social Robots Can and Should Do?, eds. Seibt J., Norskov M., Schack S., IOS Press BV, Amsterdam.

Sparrow Robert, Sparrow Linda (2006), In the hands of machines? The future of aged care, "Minds and Machines", no 16.

Vincent Sam, Brackley Jonathan (2015), Humans, Channel 4 and AMC. 